\title{
Enduring and Emerging Challenges of Informed Consent
}

A very good paper on the old and new challenges for Ethics in the current era of personalised medicine, by Christine Grady, on New England Journal of Medicine:

Grady, C. (2015). "Enduring and Emerging Challenges of Informed Consent." New England Journal of Medicine 372(9): 855-862. http://www.nejm.org/doi/full/10.1056/NEJMra1411250? rss=searchAndBrowse

For example, the boundaries between clinical care and research are "shifting": what are the right models for patient consent in 'merged' "clinical and research learning activities"?

Or how to consent for genetic testing when one considers the "substantial uncertainties", incidental findings and implications for blood relatives? One of the challenges "emerges from the complexity and uncertainty of the information generated by advanced technologies and expanded research opportunities".

The paper provides an effective summary in Table 1, including proposed strategies to address the challenges.Solutions need to be "creative, practical and respectful".

..."consent is recognized as morally transformative authorization, making certain activities permissible that otherwise would be wrong" (p.860). 